\title{
Review \\ Conservation Challenges and Emerging Trends of Digital Preservation for UNESCO Architectural Heritage, Pakistan
}

\author{
Asma Khalid
}

Citation: Khalid, A. Conservation Challenges and Emerging Trends of Digital Preservation for UNESCO Architectural Heritage, Pakistan. Conservation 2022, 2, 26-37. https:// doi.org/10.3390/conservation2010003

Academic Editor: Ioannis Liritzis

Received: 12 October 2021

Accepted: 26 December 2021

Published: 31 December 2021

Publisher's Note: MDPI stays neutral with regard to jurisdictional claims in published maps and institutional affiliations.

Copyright: (C) 2021 by the author. Licensee MDPI, Basel, Switzerland. This article is an open access article distributed under the terms and conditions of the Creative Commons Attribution (CC BY) license (https:// creativecommons.org/licenses/by/ $4.0 /)$
Department of Product and Industrial Design, University of Engineering and Technology Lahore, Lahore 54000, Pakistan; asma.khalid@uet.edu.pk

\begin{abstract}
Recent worldwide initiatives at world heritage forums, especially UNESCO, have increased the importance of architectural heritage. Architectural heritage includes built structures that are of outstanding value of natural and cultural identity and require conservation, preservation, presentation and transmission to the future generations. In this regard, UNESCO has enlisted six World Heritage Sites in Pakistan that need to be preserved. Moreover, the heritage sites are undergoing theft, vandalism, natural decay and other socio-cultural harms. One of the state-of-the-art methodologies is the digital preservation of the historic sites. Amongst the various available computer technologies, photogrammetry is the quickest and most cost-effective method that can be used for digital preservation. The research will focus on the digital preservation of UNESCO World Heritage Sites, which is an emerging trend in an architectural context. Developing countries have limited funds and resources and most historic sites are being neglected by the lack of financial resources. The paper suggests digital preservation as an emerging solution, identifies its challenges and suggests photogrammetry as a cost-effective solution to six UNESCO enlisted historic sites of Pakistan. It also suggests that once digitally recorded, information of historic sites can also be used in diverse applications to generate further finances.
\end{abstract}

Keywords: digital heritage; UNESCO; conservation challenges; photogrammetry; architectural heritage

\section{Introduction}

After the energy crisis in 1970, the world realized about the purity of the natural environment, renewable resources and ecological footprints of humans on earth. The sustainable development, as defined by Brundtland in 1987, our common future, is the equitable balance between environment, social and economic aspects, with a consideration for future generations. In this context, sustainable heritage is the identification, conservation, preservation, presentation and transmission of the natural and cultural environment to future generations. The true sense of historic architectural vernacularism is the celebration of design of climate responsive historic buildings. Buildings that stand out in their time, best respondent to climate, social, economic and cultural values are time-tested sustainable heritage. There exists empirical evidence between cultural heritage and sustainable development. Culture is developed over a long period of time, either in the past or present, sharing common goals and objectives for developing a civilization. Several studies [1-5] support the idea of safeguarding and protecting historical sites of cultural and historical character, connecting tangible and intangible values. Bob [6] also claims positively celebrating the importance of cultural diversity in the world heritage process for setting the future direction on the basis of past grounds. Religion, social development and geographical locations are a few considerable factors bonded to the heritage community and diversity.

Cultural heritage is more threatened by a globalized world, technological advancements, population explosion and political and economic instability [7]. A new set of challenges that have emerged more recently are the documentation, protection and proper management of cultural heritage. Additionally, the use of heritage information is not sustainable as it lacks a policy framework. Cultural heritage in the last few decades has been 
supported by international charters, conventions and principles, but with recent digitalized trends, it has extended towards various disciplines, tools, technologies and methodologies. This has come along with the exhaustive understanding of risk assessment and risk monitoring of historic sites, structures and monuments. However, there is a strong gap between the geomatics professional, cultural heritage creators and conservation practitioners [8].

Climate change, greenhouse gas emission and other environmental problems are adding an additional challenge. The historic buildings have also encountered the catastrophic effect of natural hazards such as floods, earthquakes, climatic conditions, etc. The magnitudes of these disastrous effects are paramount to the historic sites and structures. In developing countries of Asia, people and societies rarely value a heritage, e.g., demolishing historic sites due to religious issues, which is also creating a social chaos in world heritage vocabulary [9]. However, the solution to many problems lies in the conservation and preservation process that must be ensured through community participation, engaging local labor and using a hybrid mix of traditional and modern techniques. For example, The Burra Charter is the theoretical and practical application of cultural heritage management that provides an understanding about the cultural site, community involvement and practically implementing polices [10]. The existence of old traditional techniques to preserve and conserve the architectural building are worth admiring, whereas the true character of building geometry that has been built and developed in ancient times is far more important. The artisans and craftsmen have forgotten this and, more precisely, stopped the practices of earlier construction, such as Naqashi and Kashi Kari, etc. The solution to the forgotten knowledge partially lies in the digital preservation, where many of the conservation and preservation practices can be documented. For example, building geometry has a significant role in identifying the traditional footprint that reflects its true essence. The international practices exist that successfully demonstrated the potential of digital conservation and tools and trainings for conservationists.

\subsection{Digital Heritage}

The digital technological boom has brought advancement to the documentation, conservation and preservation techniques in the field of architectural heritage. Digital heritage, as defined by many authors [11-14], is the use of digital media in the service of preserving cultural or natural heritage. The UNESCO Charter on the Preservation of the Digital Heritage in 2003 also explains it further as: "The digital heritage consists of unique resources of human knowledge and expression. It embraces cultural, educational, scientific and administrative resources, as well as technical, legal, medical and other kinds of information created digitally, or converted into digital form from existing analogue resources."

Digital architectural heritage is the protection of the cultural heritage using digital technologies to keep intact the integrity and beauty of the built environment $[15,16]$. The advancement in technology has also provided a solution to the conservation and preservation of national and international cultural heritage. These emerging tools have given a new insight into the development and improvement in the methods of conservation and preservation of cultural values. The state-of-the-art technologies can play a vital role in the conservation, preservation and safeguarding of immovable cultural heritage. Hatzopoulos [17] used different surveying and photogrammetry techniques such as digital camera, Lidar scanner and GPS for The Tholos in Delphi, Greece, which was further used in the game application for different educational scenarios and situations.

Another problem in conservation is the requirement of funds and sponsorship, and lack of finances has led to the decay and even sometimes collapse and perish of whole historic sites and structures after a natural disaster. A cheap method of immediate recording for such sites in developing countries can be through digital conservation. For developing countries, one such example of its solicitation is at Marinids' Royal Necropolis City of Fez, Morocco [18], where they took advantage of close range photogrammetry using DSLR and smartphone cameras as low cost $3 \mathrm{D}$ modelling of historic sites. The digital conservation 
is also helpful in saving a high risk marine archeological site, using transdisciplinary approaches to preserve the Kastrouli-Antikyra Bay Land and Sea Project, Phokis, Greece [19].

\subsection{Historical, Natural and Cultural Heritage of Pakistan}

Pakistan is blessed with vast historical, natural and cultural heritage still to be explored and it requires international attention. (UNESCO) and the World Bank appreciate the importance of the nation's cultural heritage in Pakistan [20]. Pakistan heritage has a long history of diverse cultural assimilation of Muslims, Hindus, Sikh and Britishers. The far-reaching impact of heterogeneity among the art, architecture and historic evidence exists in Pakistan architectural heritage. The deep-rooted effect of Indus Valley Civilization is reflected in the famous architectural sites of Mohenjo daro, Harappa and Texila. The Indus archaeological sites and architectural structure in various cities of Pakistan are promoting multi-faceted relations of history and built environments. The Gandaha art is a legacy of buddish civilization in Pakistan's region. Similarly, the diversity of culture is reflected in Mughal architecture and pre-partition construction. The United Nations Educational, Scientific and Cultural Organization (UNESCO) has enlisted 6 World Heritage Sites (Figure 1) and 18 on a tentative list in Pakistan. These places are of outstanding cultural or natural importance to the world heritage community. The program was founded with the Convention Concerning the Protection of World Cultural and Natural Heritage, which was adopted by the General Conference of UNESCO on 16 November 1972 in Paris. Pakistan endorsed the convention on 23 July 1976, making its historical sites eligible for inclusion on the list.

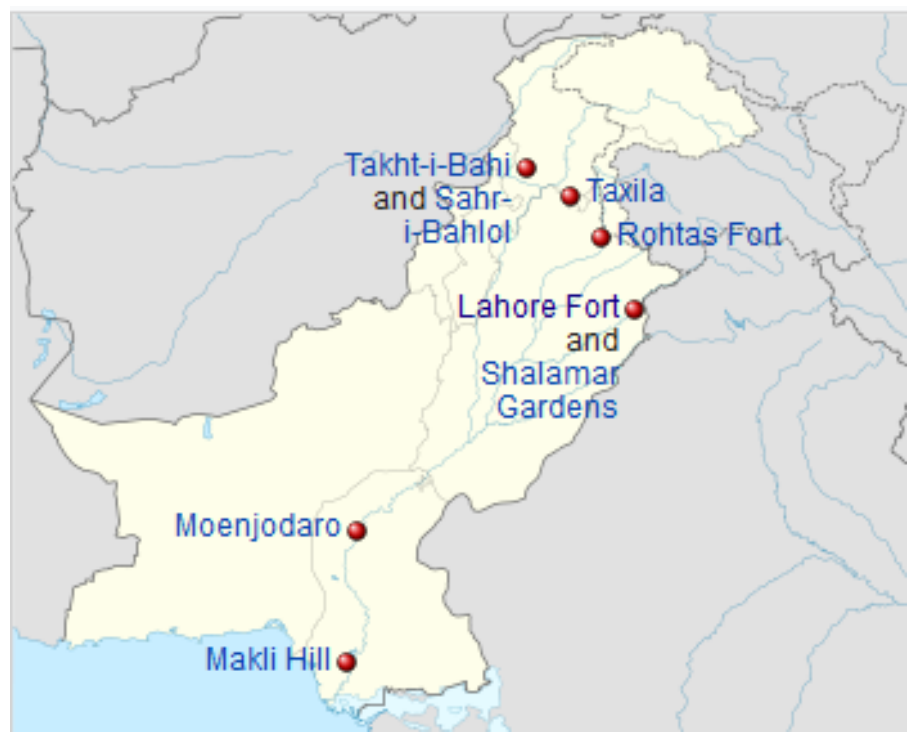

Figure 1. Location of World Heritage Sites on Pakistan's map [20].

\section{Objective}

The research aims to identify the sustainable, cheap and digital solution to the conservation practices in the field of architecture. It tends to suggest photogrammetry as digital record for the historic sites in Pakistan. The study elaborates about the importance of digital heritage, challenges faced in digital preservation of architectural heritage and the diverse application of digital preserved information.

\section{Methodology}

The study is based on the methodological review of existing literature in the field of cultural and architectural heritage and its conservation and preservation in digital format. The paper reviews various sources of information from a variety of databases, including Web of Science, Scopus, and university portals, and compiles information, challenges and 
their solutions to conservation and preservation of digital heritage. The paper suggests digital conservation of historical sites in Pakistan as identified by UNESCO. It discusses the corresponding issues of preservation which has also been highlighted by the experts in the field of conservation through the two cases of Lahore Fort and Baltit Fort. The paper tried to capture the opinion of academicians and field experts so as to bridge a gap in the field of conservation, preservation and digital recordings within Pakistan. Their insights from both projects can help in locating a pathway from the traditional to a more digitalized way of conservation. Finally, the paper concludes by suggesting photogrammetry as a cheap and quick resource to document the UNESCO heritage sites in developing countries such as Pakistan.

\section{Analysis of Case Reviews}

The two cases of Lahore Fort and Baltit Fort can help to share the insights in the field of conservation. The following questions were focused regarding two projects of digital preservation of Lahore Fort and Baltit Fort. The National Heritage and Cultural division, Government of Pakistan, has made some information publicly available regarding digital conservation of the carried-out projects. The paper discusses and reports some important information for both projects of Lahore Fort and Baltit Fort with regard to various challenges that were faced during their conservation.

Mughal architecture has an adorable, splendid beauty of its monuments, sharing the epic story of their past time, that needs to be conserved at present to let the future generation know about historic and cultural achievements. Lahore Fort and Shalimar Gardens, a beautiful blend of hard and soft scape, were built during the time of the Mughal Empire (1524 to 1752). The Lahore walled city is known to be the Gardens of Mughals due to historic monuments and old cultural landscape. With financial assistance from the Norwegian Government and Agha Khan Trust and with facilitation by the Walled City of Lahore Authority, the first phase of the Lahore Fort was documented. There are the majority of 21 monuments in the fortified space. The complete digital documentation of the west wall spans $110 \mathrm{~m}$ in length and $15 \mathrm{~m}$ in height and has been completed. The digitalization is performed with the help of a 3D laser scanner. The auto-generated 2D architectural drawings from the 3D point cloud output has helped in suggesting an appropriate conservation strategy [21]. However, the digitalization process has been applied on one wall and Alamgir Gate. There are 21 monuments in 20 acres of fortified area that need digital documentation and preservation, which is under way. Shalimar Gardens was enlisted as a World Heritage Site in 1981, a Persian utopia, built on three terraces with lodges, waterfalls and ornamental ponds. Chishti [22] examines the relationship between the physical and symbolic features of Mughal Gardens. UNESCO [23] discusses the framework in carrying out the master plan of Shalimar Gardens. It also provides a conservation priority list (emergency, stabilization, preventive conservation, conservation) for planted heritage features, water distribution and display elements, such as fountains and tanks, garden features including pavements and Chini Khana, and other structural elements of the garden.

One initiative has already been taken by CyArk for the digital storage of heritage before they are damaged. The project initiative includes the digital scanning of the Mughal vestige Picture Wall, Alamgiri Gate [Figure 2], Lahore Fort [Figure 3] and Baltit Fort [Figure 4], to save its calligraphic and Qashani work through 3D laser scanning and digital modeling. The use of 3D scanning and drone technology is being implemented and used in the preservation of Lahore Fort and various other sites internationally. It is prevalent to keep intact the virtual documentation of building geometry and its architectural features, with the original graphical texture of the building photographed. There, digital framework has been outlined in the picture wall, Alamgiri Gate and Baltit Fort, as a baseline model for the future evaluation of various other heritage sites in developing countries with limited resources and funds. 


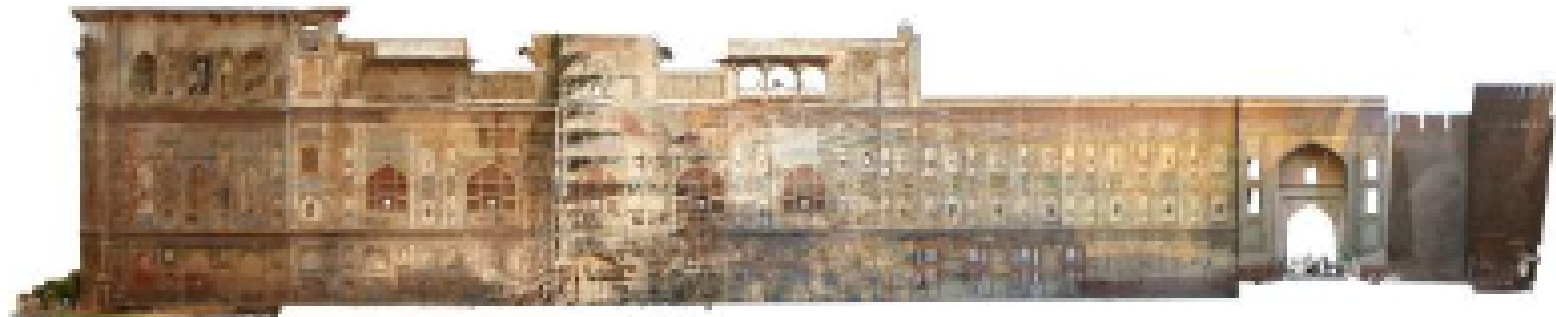

Figure 2. Digital preservation of Picture Wall.

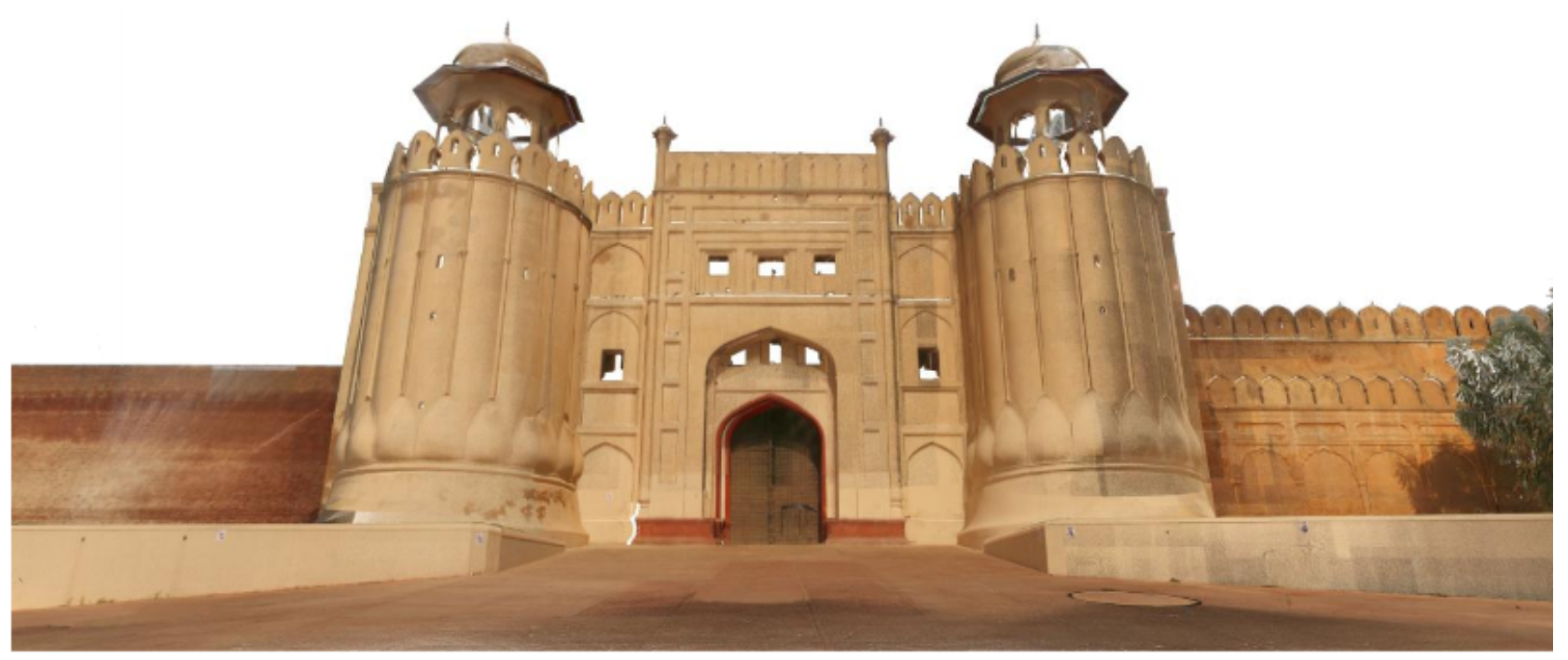

Figure 3. Digital preservation of Alamgiri Gate.

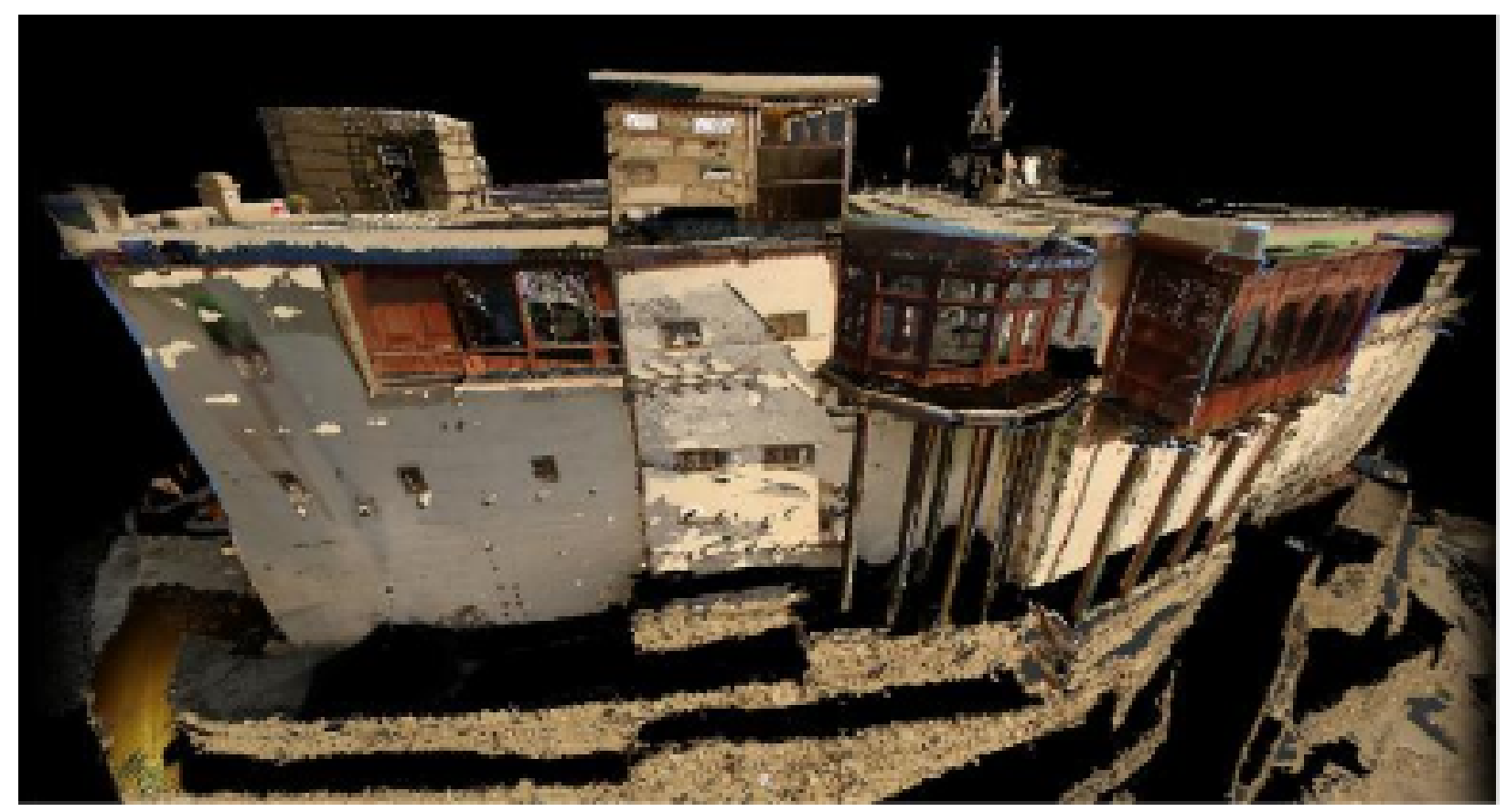

Figure 4. Digital preservation of Baltit Fort.

The following variables as shown in Table 1 have been identified regarding the current challenges in the field of digital conservation and preservation. 
Table 1. Challenges of Digital Conservation.

\begin{tabular}{llll}
\hline No. & Variables & Lahore Fort & Baltit Fort \\
\hline 1 & Challenges of digital conservation & $\boldsymbol{V}$ & \\
2 & Financial constraints & Sponsored & Sponsored \\
3 & Copyright issues & Sensitive & Sensitive \\
4 & Social barriers & $\checkmark$ & - \\
5 & Climate change barriers & Medium & High \\
6 & Lack of awareness & Medium & Medium \\
7 & Theft and vandalism in digital format & Sensitive & Sensitive \\
8 & Ignorance & $\checkmark$ & - \\
9 & New construction & $\checkmark$ & - \\
10 & Structural instability & $\checkmark$ & - \\
11 & Misuse of public property & $\checkmark$ & $\checkmark$ \\
12 & Lack of software training & - & - \\
13 & Limitation of cloud storage & - & - \\
14 & Intellectual property rights & $\boldsymbol{\checkmark}$ & Sponsored \\
15 & Maintenance of 3D laser scanning and drones & Sponsored & No \\
16 & Post use of digitalized media & No & \\
\hline
\end{tabular}

The Lahore Fort was the first project to be implemented in the context of Pakistan regarding digital conservation and it was a way forward for the Baltit Fort. So, there were many basic issues and challenges already addressed in the Pakistan context. The financial constraints were handled in both projects through sponsorship and, in the case of Lahore Fort, the Picture Wall was declared to be very sensitive, to be preserved due to decay due to climatic and environmental challenges. Both the sites are highly sensitive in terms of using the modeled project in digital format because there are no laws enforced in utilizing the digital format of documented cases. The lack of capacity building in the digital conservation field also limits the further conservation in future projects as there is strong reliability on sponsorship and funding. Figure 5 explains the relation and need of strengthening said variables.

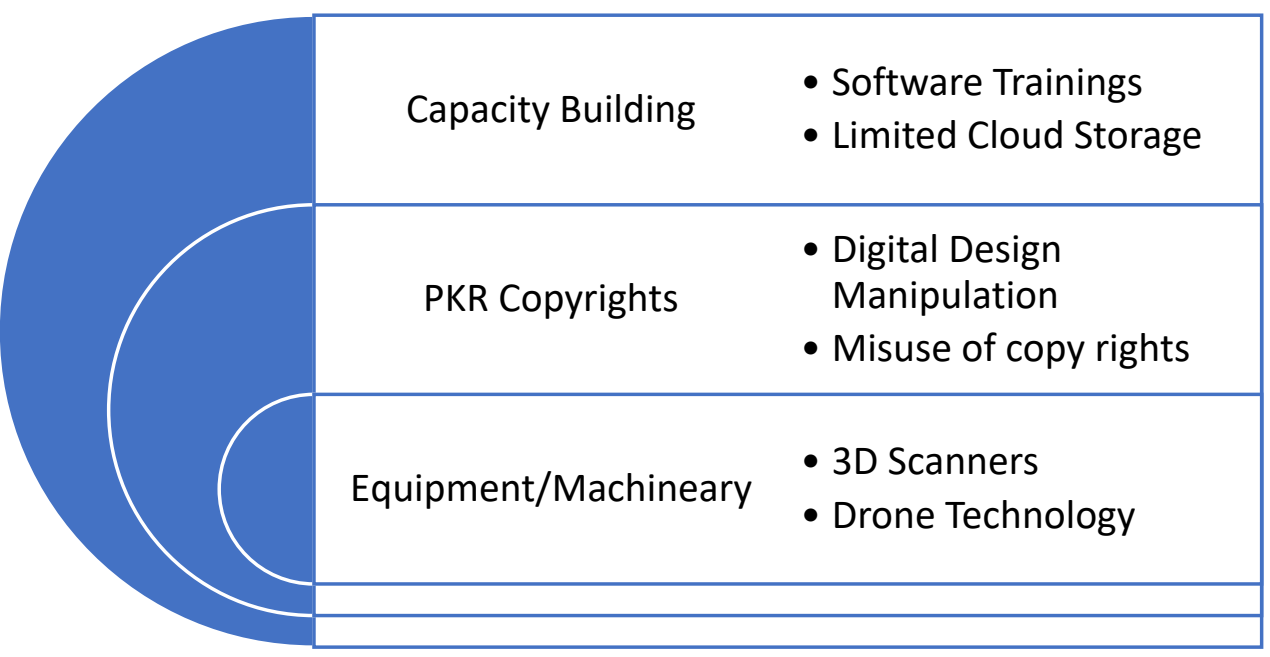

Figure 5. Capacity building of digital conservation.

Digital sustainability will remain the core of preservation and conservation as both sites are facing extreme effects of climate change, many social issues of theft and vandalism, together with financial issues (Figure 6). Although both sites are public properties, people lack awareness about saving the heritage through the traditional method of conservation for which there is no replacement. However, it is the need of time to make the best use of available technologies, through the digital way of safeguarding the national heritage sites as explained in Figure 7. 


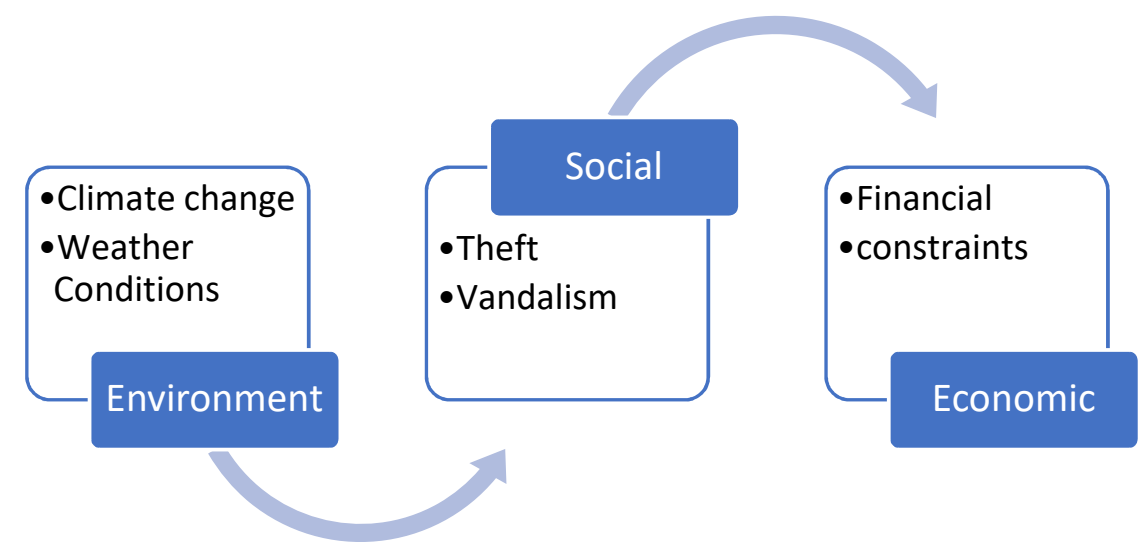

Figure 6. Digital sustainability in conservation.

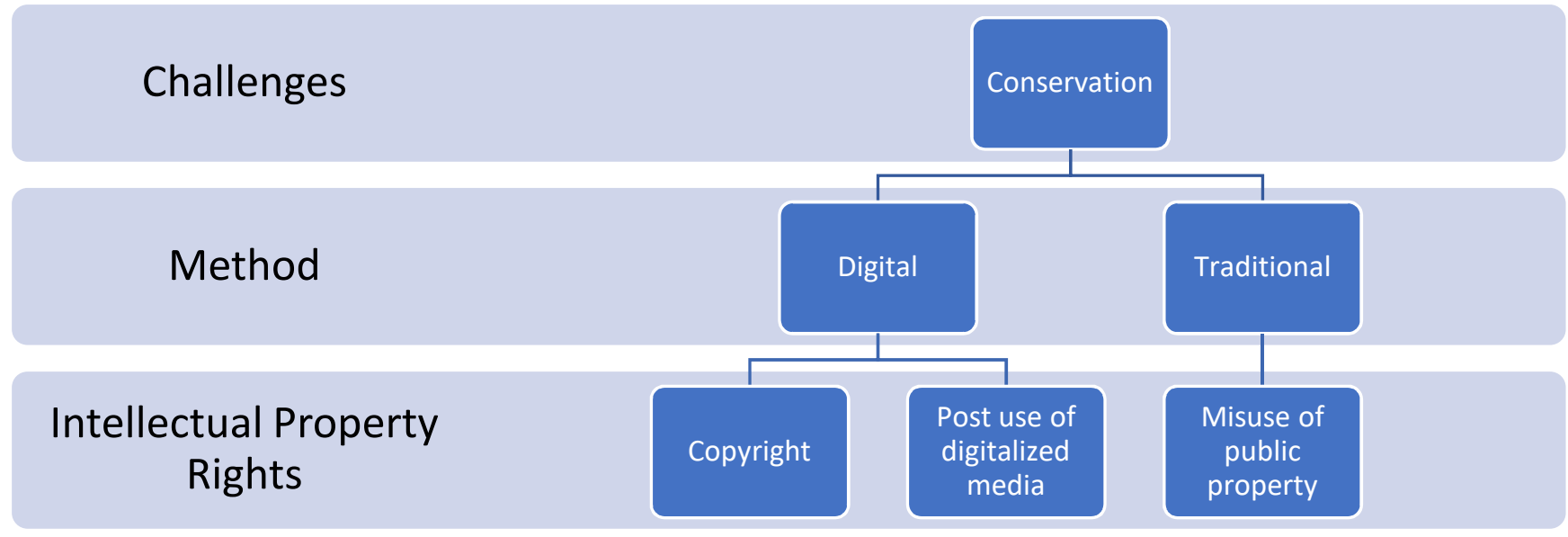

Figure 7. Comparison of Traditional verses Digital Conservation.

\section{Discussion}

Pakistan is also vernacularized to the adverse impact of unsustainable development, environmental impact and globalization. Rapid construction, urbanization, lack of awareness, ignorance, theft and vandalism of historic sites and lack of funds are a few reasons for deterioration, the extinguishing of architectural heritage in various cities of Pakistan. The feasibility study "Preservation of Endangered Moveable Culture Assets of Gandhara Art" concludes that there is no proper mechanism/system for the conservation of objects due to lack of expertise as well as human and financial resources. Lahore, historically built around 4000 years ago in 2000 B.C.E., is contemporaries with the Indus Valley Civilization that lies on the northwestern coast of India and Pakistan [24,25]. The following issues have been identified in Pakistan's World Heritage Sites:

1. There have been serious threats and damage caused due to the environment. The fragile nature of historic structures is being widely affected by the climatic conditions and harsh weather. The monsoon rains of summers have led to deterioration of existing structures in many cases, such as mosaics, fresco, brick work and murals. At the same time, hot summers with sunny weather also cause decay and building color fading away.

2. The tourism, on one hand, has made the historical sites a capturing point for visitors and, on the other hand, it has badly affected the architectural heritage.

3. The lack of funds available has led to delayed and inappropriate conservation of UNESCO sites in Pakistan.

4. The poor documentation and lack of training skill and expertise are also a bigger cause of the decay in UNESCO sites in Pakistan. 
The architectural ruins at these UNESCO sites are the clear proof of neglect and vandalism.

So, the existing structure of World Heritage Sites in Pakistan is posing an enormous challenge for preserving the originality of natural and cultural heritage. The conservation of these monuments requires immediate attention to safeguard the national heritage. The Department of Archaeology has taken a few initiatives at different times, depending on resources available, to save these cultural spots. The documentation of historical structures and buildings, in the original and true sense, and with complete process coverage of their material conservation is important for today and future generations, who will maintain the past. Technology has played a very important role in revolutionizing the state of art for the preservation and conservation of historical structures.

\subsection{Challenges in Digital Heritage}

Studies [26-30] emphasize the importance of digital application in the field of conservation and preservation. Many historians and conservationist [31-33] explained the concept of digital heritage as "easy in sharing of cultural products, has increased global dissemination and promotes intercultural communication". However, in Pakistan, it has been called upon as new heritage in a digital world, where new challenges of copyright, property law and ownership do not exist. The revolutionized computer technologies, on one hand, have made the access to heritage and cultural objects independent of time and space and, on the other hand, increased the technical threats of data format, saving operating systems and compatibility issues, which has made digital preservation a difficult task.

Hassani [34] also aims to convince people of the more logical use of newly available digital technologies in the field of conservation. On one side, the digital formats are readily accessible information on the heritage collection and preservation and can be used for many productive reasons, including entertainment and educational purposes. On one hand, the digital formats of documentaries, video, images, virtual game, films and audio recordings will protect them and then make them easily accessible to people for the information of natural cultural heritage. At the same time, The UNESCO Charter has highlighted its concerns regarding digital preservation. These digital formats are perishable databases, non-reliable with many technological limitations that still need innovation [35-37]. In this regard, UNESCO has made an enormous contribution through its Charter for the preservation of intellectual world heritage. That is why [38,39] have linked digital heritage with virtual reality, based on the perception of individuals' interaction, the creations of actual feel with the use of all olfactory senses necessary to participate to enjoy virtual cultural heritage. However, the virtual feel can never be a match for the feel of natural heritage, tangibly felt and enjoyed.

\subsection{Lack of Standardization}

Additionally, standardization, the lack of guidelines in digital preservation, has made it difficult for conservationists, archaeologists and architects to preserve electronic data. At the same time, the multiplication of digitalized objects, their authenticity to the original, is also ignored and requires immediate attention. The digital platform requires the development of universal standardized laws and their enforcement with penalties. The copyright issues and their keen acceptability at the forums of UNESCO is very important.

In the special context of Pakistan, there is a lack of adopting and applying the international charters, conventions and principles on documentation of cultural heritage, especially for all UNESCO identified sites. The conservation, monitoring and management must be brought forth with full protocols and as an integral part of digital preservation, valuing its cultural significance. Additionally, these charters, conventions and principles must include the standardized practice to adapt cultural heritage information in any digital format with universal standardization practiced through the platforms of UNESCO. 


\section{Photogrammetry, a Quick Resource of Digital Preservation}

Photogrammetry is another way through for quick digital documentation for the remaining five UNESCO enlisted monuments in Pakistan. It is a quick, cheap, easily available resource that requires software training to professionals. Photogrammetry can be defined as "the art, science, and technology of obtaining reliable information about physical objects and the environment through the processes of recording, measuring, and interpreting photographic images". Photogrammetry is the most recent and efficient way of taking measurements using photographs. This creation of a 3D model is possible because of recovering the exact positions of surface points. Various studies [40-43] demonstrated the successful application of photogrammetry on various historic buildings and antiquities worldwide. Lee and Dorcic [44,45] use personalized smart phone technology for the study of photogrammetric application. These studies provide a quick overview of a photogrammetric collection of virtual 3D models. Among the six listed sites in Pakistan on the UNESCO world heritage list, Shalimar Gardens is selected for the application of digital technologies. The survey of the Shalimar Gardens will be conducted to document its architectural detail using photogrammetric techniques. The camera photography can be used to record the physical configuration of the exterior facades, interior walls, detail of mural, frescos, geometric patterns at the floor and roof paintings and carvings. This technique will also allow capturing detailed views of the site and environment of Shalimar Gardens with high-resolution photographic images.

The PhotoModeler software is a cost-effective way for accurate 3D scanning, measurement, surveying and reality capture. In order to create a detailed 3D geometry, the photographic images of Shalimar Gardens will be imported in PhotoModeler software. The software uses bundle adjustment methods to create 3D models of Shalimar Gardens. The photographs are manually matched for the common features or smartly matched to create dense cloud points from overlapping different surveyed photos [46]. Through the application of photogrammetric, the digital model of Shalimar Gardens will be created and documented. The construction of the detailed geometry and its architectural minutiae and intricacy of facades and other landscape features can be documented and preserved through PhotoModeler simulation. Finally, a theoretical framework model will be developed as a futuristic approach for the application of digital heritage studies of different buildings in Pakistan. The framework will use multistage methodology to achieve its objectives and will become a baseline study for the further investigation, improvement in digital preservation and conservation of Shalimar Gardens. Shalimar Gardens can be conserved for its historic landscape using the low cost high-resolution DSLR (Digital Single-Lens Reflex) cameras, commonly available and documented using a cloud to cloud method as used in [18]. The degree of accuracy will be higher for ground control points and bundle adjustments in 3D coordinates.

\section{Diverse Application of Digital Preservation}

Digital preservation is also being used as the tool to educate students about the technological advancement in the field of conservation, as we have seen an example of such application in [17]. This practice is being adopted by many institutes all over the world to educate and train students in the field of digital preservation. Liritzis [47] demonstrate the potential emergence of digital technologies in cultural heritage that have brought a revolution in the virtual world, such as digital fabrication and cloud computing, and have become trans-disciplinary in nature to adapt the naturistic influences. The most diverse and recent application of the digital conservational technologies is in various fields of cyber archaeometry, virtual archaeology, gamification through virtual and augmented reality. This will help to increase digital access for the museum audience through web possibilities at any location in the world to experience Pakistan culture [18]. After the successful development and implementation of copyright laws that can be universally practiced through the UNESCO platform, the digitally preserved heritage can be used in IMAX and virtual reality experiences for historic and valuable architectural sites. It will increase the 
charity donation at UNESCO and UN ambassador level, especially in developing countries where these historic sites are being neglected by the lack of funds, and retaining its original geometry, material colors and texture in digital formats. In addition to that, the virtual experience of various sites will be available where it is not possible for many individuals to physically go there and experience those places due to financial issues and medical reasons. Digital preservation will also make a strong emotional bond with old classical built heritage through the virtual environment.

Funding: The Research received no external funding.

Institutional Review Board Statement: Not applicable.

Informed Consent Statement: Not applicable.

Data Availability Statement: Not applicable.

Conflicts of Interest: The authors declare no conflict of interest.

\section{References}

1. Remondino, F. Heritage recording and 3D modeling with photogrammetry and 3D scanning. Remote Sens. 2011, 3, 1104-1138. [CrossRef]

2. Tweed, C.; Sutherland, M. Built cultural heritage and sustainable urban development. Landsc. Urban Plan. 2007, 83, 62-69. [CrossRef]

3. Gullino, P.; Beccaro, G.L.; Larcher, F. Assessing and monitoring the sustainability in rural world heritage sites. Sustainability 2015, 7, 14186-14210. [CrossRef]

4. Merino-Aranda, A.; Castillejo-González, I.L.; Velo-Gala, A.; Montes-Tubío, F.D.P.; Mesas-Carrascosa, F.J.; Triviño-Tarradas, P. Strengthening efforts to protect and safeguard the industrial cultural heritage in montilla-moriles (Pdo). characterisation of historic wineries. Sustainability 2021, 13, 5791. [CrossRef]

5. Hernàndez-Cardona, F.X.; Sospedra-Roca, R.; Íñiguez-Gracia, D. Educational illustration of the historical city, education citizenship, and sustainable heritage. Sustainability 2021, 13, 5706. [CrossRef]

6. Bob Giddings, B.H.; O'brien, G. Environment, economy and society: Fitting them together into Sustainable Development. Sustain. Dev. 2002, 10, 187-196. [CrossRef]

7. Erica Avrami, Randall Mason, Marta de la Torre. Values and Heritage Conservation. In Research Report The Getty Conservation Institute, Los Angeles. 2000. Available online: https:/ / www.getty.edu/conservation/publications_resources/pdf_publications/ pdf/valuesrpt.pdf (accessed on 4 December 2021).

8. Haddad, N.A.; Fakhoury, L.A.; Sakr, Y.M. A critical anthology of international charters, conventions \& principles on documentation of cultural heritage for conservation, monitoring \& management. Mediterr. Archaeol. Archaeom. 2021, 21, 291-310. [CrossRef]

9. Viñas, S.M. Contemporary theory of conservation. Contemp. Theory Conserv. 2012, 2012, 1-239. [CrossRef]

10. Hanna, B. Innovation in Conservation: A Timeline History of Australia ICOMOS and the Burra Charter. 2017, No. January 2016, 92. Available online: https://www.researchgate.net/publication/316924146_Innovation_in_Conservation_a_Timeline_History_ of_Australia_ICOMOS_and_the_Burra_Charter (accessed on 4 December 2021).

11. Bruton, D. Theorizing Digital Cultural Heritage: A Critical Discourse. Inf. Commun. Soc. 2011, 14, 1077-1078. [CrossRef]

12. He, Y.; Ma, Y.H.; Zhang, X.R. Digital heritage theory and innovative practice. Int. Arch. Photogramm. Remote Sens. Spat. Inf. Sci. ISPRS Arch. 2017, 42, 335-342. [CrossRef]

13. UNESCO. Digital Heritage. Available online: https://en.unesco.org/themes/information-preservation/digital-heritage (accessed on 4 December 2021).

14. Division, I.S.; Specialist, S.P. Charter on the Preservation of the Digital Heritage. 2009, Volume 33. Available online: www.unesco. org (accessed on 4 December 2021).

15. Brusaporci, S. Digital Innovations in Architectural Heritage Conservation: Emerging Research and Opportunities: Emerging Research and Opportunities. Available online: https://www.researchgate.net/profile/Stefano-Brusaporci/publication/315445172 Digital_Innovations_in_Architectural_Heritage_Conservation_Emerging_Research_and_Opportunities/links/58cfefccaca272 70b4acdfb2/Digital-Innovations-in-Architectural-Heritage-Conservation-Emerging-Research-and-Opportunities.pdf (accessed on 4 December 2021).

16. Lopes, R.O.; Malik, O.A.; Kumpoh, A.A.Z.A.; Keasberry, C.; Hong, O.W.; Lee, S.C.W.; Liu, Y. Exploring digital architectural heritage in Brunei Darussalam: Towards heritage safeguarding, smart tourism, and interactive education. In Proceedings of the 2019 IEEE 5th International Conference on Multimedia Big Data, BigMM 2019, Singapore, 11-13 September 2019 ; pp. 383-390. [CrossRef] 
17. Hatzopoulos, J.N.; Stefanakis, D.; Georgopoulos, A.; Tapinaki, S.; Pantelis, V.; Liritzis, I. Use of various surveying technologies to 3D digital mapping and modelling of cultural heritage structures for maintenance and restoration purposes: The Tholos in Delphi, Greece. Mediterr. Archaeol. Archaeom. 2017, 17, 311-336. [CrossRef]

18. Khalloufi, H.; Azough, A.; Ennahnahi, N.; Kaghat, F.Z. Low-cost terrestrial photogrammetry for 3d modeling of historic sites: A case study of the marinids' royal necropolis city of fez, morocco. Mediterr. Archaeol. Archaeom. 2020, 20, 257-272. [CrossRef]

19. Levy, T.E.; Sideris, T.; Howland, M.; Liss, B.; Tsokas, G.; Stambolidis, A.; Fikos, E.; Vargemezis, G.; Tsourlos, P.; Georgopoulos, A.; et al. At-Risk World Heritage, Cyber, and Marine Archaeology: The Kastrouli-Antikyra Bay Land and Sea Project, Phokis, Greece. In Cyber-Archaeology and Grand Narratives; Springer: Cham, Switzerland, 2018. [CrossRef]

20. UNESCO. Pakistan-UNESCO World Heritage Centre. Available online: https://whc.unesco.org/en/statesparties/pk (accessed on 4 December 2021).

21. Arif, R.; Essa, K. Evolving techniques of documentation of a world heritage site in Lahore. Int. Arch. Photogramm. Remote Sens. Spat. Inf. Sci.-ISPRS Arch. 2017, 42, 33-40. [CrossRef]

22. Chishti, R.; Seemi, I.; Mujeeb, Z.H. The Shalamar Gardens Lahore: A Case Study of Mughal Garden Design and Concept. Putaj Humanit. Soc. Sci. 2007, 24, 100-107.

23. UNESCO. UNESCO World Heritage Centre-State of Conservation (SOC 2008) Fort and Shalamar Gardens in Lahore (Pakistan) Available online: http:/ / whc.unesco.org/en/soc/791 (accessed on 4 December 2021).

24. Cities, M.H.; Role, T.; Partnerships, P. Walled City of Lahore Project Multi-Agency Collaboration for Urban Rehabilitation in Pakistan. 2007; pp. 7-10. Available online: https:/ /www.into.org/app/uploads/2020/11/Pakistan-Lahore.pdf (accessed on 4 December 2021).

25. Wilson, Q.C. The Adobe Construction Program Curriculum at Northern New Mexico College, USA. Available online: https: //nnmc.edu/adobe-construction/ (accessed on 4 December 2021).

26. Rahaman, H.; Champion, E.; Bekele, M. From Photo to 3D to Mixed Reality: A Complete Workflow for Cultural Heritage Visualisation and Experience. Digit. Appl. Archaeol. Cult. Herit. 2019, 13, e00102. [CrossRef]

27. Vrettakis, E.; Kourtis, V.; Katifori, A.; Karvounis, M.; Lougiakis, C.; Ioannidis, Y. Narralive-Creating and experiencing mobile digital storytelling in cultural heritage. Digit. Appl. Archaeol. Cult. Herit. 2019, 15, e00114. [CrossRef]

28. Thwaites, H.; Santano, D.; Esmaeili, H.; See, Z.S. A Malaysian cultural heritage digital compendium. Digit. Appl. Archaeol. Cult. Herit. 2019, 15, e00116. [CrossRef]

29. Economou, M. Heritage in the Digital Age. In A Companion to Heritage Studies; John Wiley \& Sons, Inc.: Hoboken, NJ, USA, 2015; pp. 215-228. [CrossRef]

30. Terras, M. Digital Heritage: Applying Digital Imaging to Cultural Heritage. Lindsay MacDonald (ed.). Lit. Linguist. Comput. 2007, 23, 244-246. [CrossRef]

31. Fowler, P.; Centre, W.H. World heritage cultural landscapes, 1992-2002: A review and prospect. Cult. Landsc. Chall. Conserv. 2002, 16, 6-135.

32. Stamatopoulou-Robbins, E. Appendix One. Universal Declaration on Cultural Diversity. In Cultural Rights in International Law; Brill: Leiden, The Netherlands, 2009; pp. 261-268. [CrossRef]

33. Disko, S. World Heritage and UNESCO Chair in Heritage Studies. In World Heritage and Cultural Diversity. 2010. Available online: https:/ / www.unesco.de/sites/default/files/2018-07/world_heritage_and_cultural_diversity_2010.pdf/ (accessed on 4 December 2021).

34. Hassani, F. Documentation of cultural heritage techniques, potentials and constraints. Int. Arch. Photogramm. Remote Sens. Spat. Inf. Sci.-ISPRS Arch. 2015, 40, 207-214. [CrossRef]

35. UNESCO. UNESCO Database of National Cultural Heritage Laws. Available online: https://en.unesco.org/cultnatlaws (accessed on 4 December 2021).

36. UNESCO. UNESCO Database of National Cultural Heritage Laws I United Nations Educational, Scientific and Cultural Organization. Available online: http:/ / www.unesco.org/new/en/culture/themes/illicit-trafficking-of-cultural-property/unescodatabase-of-national-cultural-heritage-laws/ (accessed on 4 December 2021).

37. UNESCO. UNESCO World Heritage Centre. Available online: http://whc.unesco.org/ (accessed on 4 December 2021).

38. Tan, B.K.; Rahaman, H. Virtual Heritage: Reality and Criticism. In Joining Languages, Cultures and Visions: CAADFutures 2009; 2009; pp. 143-156. Available online: http://cumincad.scix.net/data/works/att/cf2009_143.content.pdf (accessed on 4 December 2021).

39. Arrighi, G.; See, Z.S.; Jones, D. Victoria Theatre virtual reality: A digital heritage case study and user experience design. Digit. Appl. Archaeol. Cult. Herit. 2021, 21, e00176. [CrossRef]

40. Baik, A.; Alitany, A. From architectural photogrammetry toward digital architectural heritage education. Int. Arch. Photogramm. Remote Sens. Spat. Inf. Sci.-ISPRS Arch. 2018, 42, 49-54. [CrossRef]

41. Cheng, H.M.; Yang, W.B.; Yen, Y.N. BIM applied in historical building documentation and refurbishing. Int. Arch. Photogramm. Remote Sens. Spat. Inf. Sci.-ISPRS Arch. 2015, 40, 85-90. [CrossRef]

42. Shashi, M.; Jain, K. Use of Photogrammetry in 3D modeling and visualization of buildings. J. Eng. Appl. Sci. 2007, 2, 37-40.

43. Salleh, N.H. Architectural photogrammetry for the recording of heritage buildings: AN Overview. J. Arch. Plan. Constr. Manag. 2012, 2, 1-19.

44. Lee Ventola, C. Mobile devices and apps for health care professionals: Uses and benefits. Pharm. Ther. 2014, 39, 356-364. 
45. Dorcic, J.; Komsic, J.; Markovic, S. Mobile technologies and applications towards smart tourism-State of the art. Tour. Rev. 2019, 74, 82-103. [CrossRef]

46. PhotoModeler. Photogrammetry |3D Measurements from Photos I PhotoModeler. Available online: https://www.photomodeler. com/ (accessed on 4 December 2021).

47. Liritzis, I.; Al-Otaibi, F.M.; Volonakis, P.; Drivaliari, A. Digital technologies and trends in cultural heritage. Mediterr. Archaeol. Archaeom. 2015, 15, 313-332. [CrossRef] 